\title{
Optimal Planning for Electric Vehicle Charging Station Considering the Constraint of Battery Capacity
}

\author{
Ming Zeng ${ }^{1,2}$, Xiaohui Zhan ${ }^{1,2}$ and Yuanfei $\mathrm{Li}^{1,2}$ \\ ${ }^{1}$ State Key Laboratory for Alternate Electrical Power System with Renewable Energy Sources, North China Electric Power \\ University, Beijing 102206, China \\ ${ }^{2}$ School of Economics and Management, North China Electric Power University, Beijing 102206, China
}

\begin{abstract}
Planning EV charging stations reasonably is significant to the development of whole $\mathrm{EV}$ industry. Taking constraints of charging capacity and investment limitation into account, the optimization model of EV charging station planning with the objective function of minimum annual cost is established. Constraint of service radius is replaced by constraint of battery capacity which takes the factor of $\mathrm{EV}$ itself in order to eliminate the possible planning failure. The model is solved by the chaos and harmony search algorithm and the optimal result of the charging stations planning is obtained. Case analysis shows that the method proposed in this paper has a certain practical and scientific, and can provide some reference for the planning of $\mathrm{EV}$ charging stations.
\end{abstract}

Keywords-electric vehicle; charging station; battery capacity, chaos and harmony search algorithm

\section{INTRODUCTION}

With the economic development and the growing contradiction between energy supply and environment pollution, the existing development model is unsustainable. So social economic must shift to the model of high efficiency and low emission. Against this background, the research and discussion of the global power industry about microgrid, EVs and so on, has become the hot topic in recent years ${ }^{[1-2]}$ 。 As an important part of the EV facilities construction, the construction of EV charging station is essential to the development of entire EV industry.

EV charging station planning is a nonlinear optimization problem with multi variables and multi constraints. In order to solve this kind of problem, many methods have been proposed. Common methods include mathematical optimization methods (such as linear programming ${ }^{[3]}$ and nonlinear programming ${ }^{[4]}$ ), heuristic optimization methods and intelligent optimization methods (such as tabu searching method ${ }^{[5]}$, genetic algorithm ${ }^{[6]}$, simulated annealing method [7], and particle swarm optimization method ${ }^{[8]}$, etc.) Many methods for solving the problem of the planning of EV charging stations were presented by some papers. Paper [9] analyses factors that affect the capacity of charging station. In paper [10], through the analysis of the electric vehicle charging demand, the factors affecting the electric vehicle charging station planning are proposed, and the principles of the layout planning are put forward. Paper [11] simulates the number of EV according to the distribution of resident load. AHP method is used to calculate the weight coefficient of each candidate station, based on which the optimal economic model of EV charging station is established. However, all these method fail to take some factors, especially factors from VE itself, which affect the charging station planning into account when building mathematic models.

Aiming at this problem, this paper, based on the existing planning ideas, will introduce capacity constraints of EV into the model. Therefore the maximum economic benefits of the charging station location, which takes both the traffic network and the electric vehicle itself into account can be realized. Using chaos and harmony search algorithm to solve the model. The scientificalness of the proposed method is demonstrated by a case analysis.

\section{Model for EV Charging Station PlanNing}

\section{A. Cost minimization Objective Function}

From the point of view of mathematics, the problem of EV charging station planning is a typical problem of location selecting and capacity determining. In the area of traffic and mathematics, there have been a very good location theory to help decision makers or analysts to weigh different planning objectives ${ }^{[12]}$. The traditional planning idea is to divide the charging demand area in the selected planning area. Then, the total annual cost minimization objective function is constructed. By optimization, the capacity and location of EV charging stations can be determined. According to that idea, the mathematical model can be described by following equations.

$$
\begin{gathered}
\min C=C_{1}+C_{2}+C_{3} \\
C_{1}=\sum_{j=1}^{m} \alpha_{j} A_{j}\left[\frac{i(1+i)^{n}}{(1+i)^{n}-1}\right]
\end{gathered}
$$




$$
\begin{gathered}
C_{2}=\sum_{j=1}^{m} A_{j}(1+\rho) \\
C_{3}=C_{0} D^{y} N^{d} \sum_{j=1}^{m} \sum_{b \in B_{j}} \beta_{b j} S_{b j} \eta_{b j} Y_{b}
\end{gathered}
$$

In equations above, $C_{1}$ stands for the annual fixed cost of building a charging station; $C_{2}$ stands for the annual operation and maintenance costs of charging stations; $C_{3}$ stands for the annual charging costs of EV users. $m$ stands for the number of charging stations needs to be built; $A_{j}$ stands for the present value of building charging station $j ; i$ stands for the discount rate; $n$ stands for years in return of capital investment, $\alpha_{j}$ stands for variable, $\alpha_{j}=1$ means that the charging station $j$ is selected; $\rho$ stands for conversion coefficient; considering EV will loss while driving, $C_{0}$ stands for the loss cost of a single $\mathrm{EV}$ in unit distance traveling; $D^{y}$ stands for the number of days per year, $N^{d}$ stands for the times of charging per user on average, which can be determined by the following equation.

$$
N^{d}=\frac{p h}{Q}
$$

$p$ stands for the consumption of electricity of EV per hundred kilometers; $h$ stands for daily driving distance of $\mathrm{EV}$ on average; $Q$ stands for the battery capacity of EV. $B$ stands for the collection in which users in the community $b$ get their EVs charged in station $j . \beta_{b j}$ is $0-1$ variable, $\beta_{b j}=1$ means that users in the community $b$ only goes to station $j$ in a certain time period. Besides, this variable should satisfy another equation as follows.

$$
\sum_{j=1}^{m} \beta_{b j}=1
$$

$S_{b j}$ stands for the distance between the community $b$ and charging station $j ; \eta_{b j}$ stands for the road condition coefficient; $Y_{j}$ stands for the number of $\mathrm{EV}$ in the community $b$.

\section{B. Constraints}

1) Constraint of charging capacity of charging stations

$$
\begin{gathered}
E_{j}=\frac{P D^{y} \sum_{b} \beta_{b j} Y_{b}}{t_{u} \sigma f r\left(E_{j}\right) \cos \varphi_{j}} \\
\sum_{b \in B} P_{b} \leq E_{j} e\left(E_{j}\right) \cos \varphi_{j}
\end{gathered}
$$

In equations above, $E_{j}$ stands for the capacity of the charging station $j . P$ stands for the charging power of each EV. $t_{u}$ stands for the daily time under charging mode $u$. At present, two modes are considered, which are fast charge and conventional charge. $\sigma$ stands for charging efficiency. $f$ stands for the demand factor of charger; $e\left(E_{j}\right)$ stands the load rate of charging station; $\cos \varphi_{j}$ stands for the power factor of charging station.

2) Constraint of investment limitation

$$
\sum_{j=1}^{m} A_{j} \leq M
$$

$M$ stands for the limitation of investment.

3) Consideration of EV battery capacity constraint

Most of the existing planning methods, only consider the service radius of charging stations and take it as a constraint. However, in urban traffic, the service radius and the length of the EV driving path are different. Not considering the characteristics of the traffic network will lead to increased driving distance of electric vehicles, sometimes beyond the mileage of EV. An example is given in Fig.1. A user lives in point $\mathrm{A}$, there are charging stations in both point $\mathrm{A}$ and $\mathrm{B}$ which service radius are $25 \mathrm{KM}$. The mileage of $\mathrm{EV}$ is $50 \mathrm{KM}$. It's obviously that this station planning can satisfy the service radius constraint. However if the user wants to drive to point $\mathrm{C}$ and returns back to point $\mathrm{A}$. The actual driving distance of $\mathrm{EV}$ is $80 \mathrm{KM}$, which is longer than $50 \mathrm{KM}$, the distance between point $\mathrm{A}$ and $\mathrm{B}$.

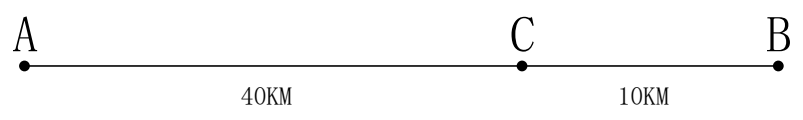

FIGURE I. CASE OF PLANNING FAILURE

At this circumstances, the user will have to drive to point B and get his EV charged or he can't return back to point A. Therefore, if there is only one station on the driving path, it's possible that EV can't reach the destination or complete a return trip smoothly (time of user is wasted in this example, it can be worse in other cases). To solve this problem, this paper replace the service radius constraint with the battery capacity constraint based on the structure of traffic network.

It's assumed in this paper that the electric quantity of $\mathrm{EV}$ at starting point $(\mathrm{F})$ is $x \% Q$ (If starts from charging station, 
assume EV is full charged.) Then EV drives to the nest point (T) on the path. The consumption of this distance is $E_{F-T}$, so the electric quantity arriving at next point is $E_{T}=E_{F}-E_{F-T}$. If there is a charging station on this point, $E_{T}=Q$. When the remaining power is not enough to maintain EV traveling to the next node, or can not return on any point on the path to last node, consider that the EV charging station planning can not meet the charging needs of this path. Considering the battery capacity constraint, an inspection procedure will be added in order to test the planning results of the traditional method.

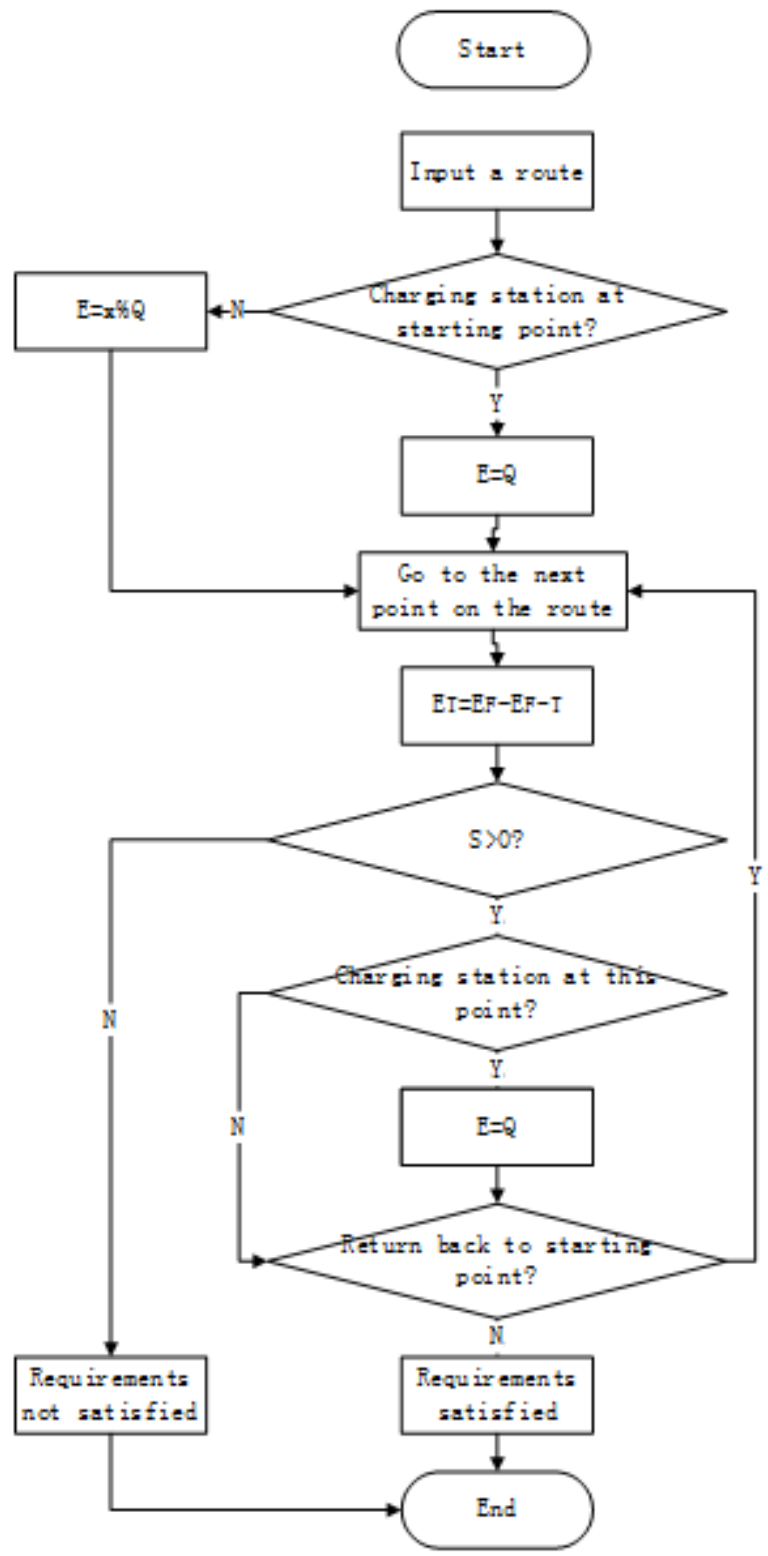

FIGURE II. INSPECTION PROCEDURE OF BATTERY CAPACITY CONSTRAINT

\section{ChaOs Harmony SEARCH AlgORithm}

In this paper, the Chaos Harmony Search Algorithm (CHS) is used to solve the traditional method ${ }^{[13]}$. In this practical problem, the harmony of musical instrument tones in CHS represents the optimal operation of each equipment. The aesthetic evaluation of the harmony corresponds to the function value of the objective function. The worst harmony is the vector of using capacity of each device which maximizes the objective function value. And the best harmony is the vector of using capacity of each device which minimizes the objective function value. The calculation steps of Chaos harmony search algorithm as follows:

1) Initialization parameter: the initial value of $\mathrm{N}$ tones(the harmony of each musical instrument tone represents a group of Chaos), the harmony memory(HM), the number of harmony which can be saved in HM(HMS), the largest number of iterations $\left(N_{\max }\right)$, the retention of harmony memory $(H M C R)$, memory disturbance probability(PR) and so on.

2) Initialize the harmony memory: First, using chaotic systems to mapping the ergodicity of chaos of equation when the control parameter $\mathrm{u}=4$. Then, initializing the feasible solution, and preferentially selecting HMS solutions into HM as the initial solution group of the algorithm to initialize the feasible solutions.

3) Through the retention of harmony memory, random selection of tones and random disturbance, it will produce a new solution $X_{n e w}$, and compared with the worst solution of harmony memory, then eliminating the poor to update the HM.

4) When the number of iterations has reached the maximum number of iterations $N_{\max }$, the output is the optimal result, and the algorithm is over.

Perform inspection procedure on the obtained optimal result. If the constraint of battery capacity is satisfied, then take the result as final result. Unless, re-initialize the harmony memory bank and perform the CHS again.

The specific process as shown in figure 3 : 


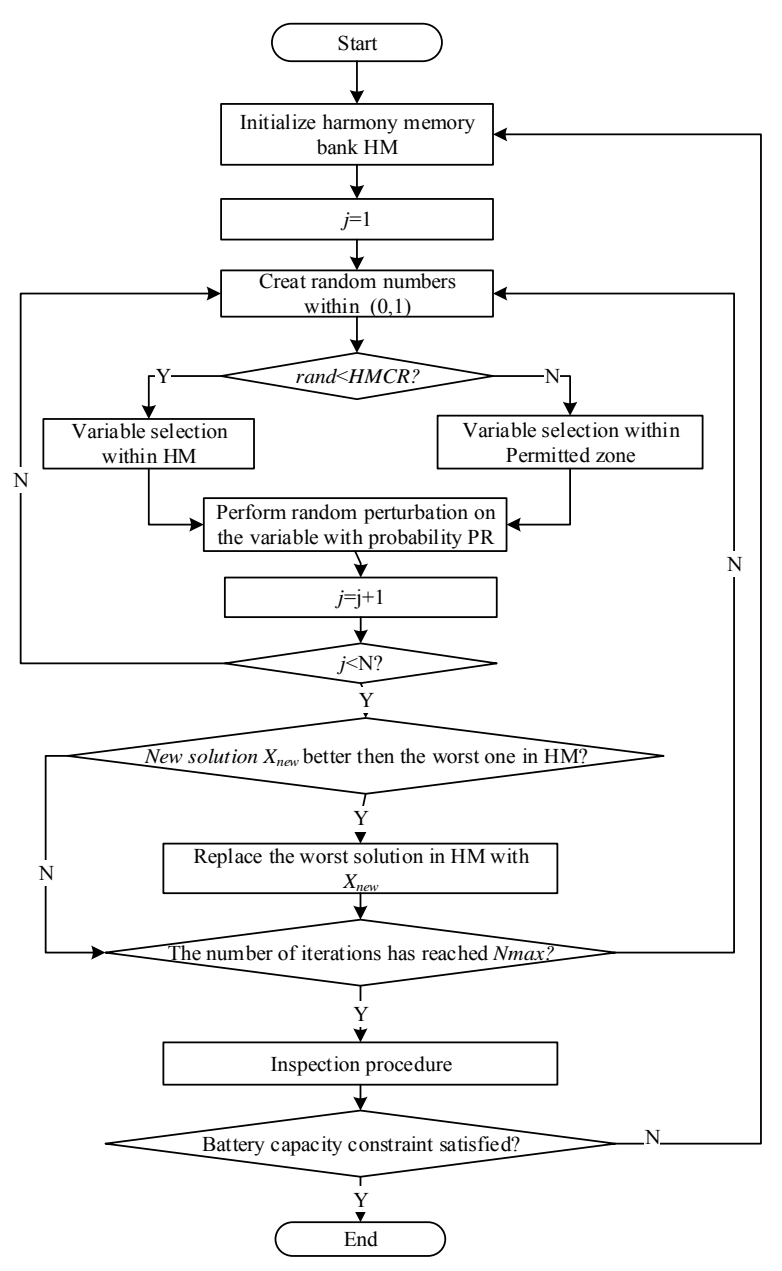

FIGURE III. THE SPECIFIC PROCESS OF CHS AND INPECTION PROCEDURE

\section{CASE ANALYSIS}

The proportion of planning area is $10.5 \mathrm{~km}^{2}$. The number of EV during planning time period is 2190 . The coordinate and number of each community is given in table 1 and the coordinate of charging station candidates are given in table 2 . The location of charging demand communities, charging station candidates and the traffic network are showed in figure 4. It's assumed that the number of EV doesn't change during planning time period, the ratio of fast charge user is $80 \%$ and the charging power of this mode is $50 \mathrm{KW}$; the ratio of conventional charge user is $20 \%$ and the charging power of this mode is $20 \mathrm{KW}$. On average, every EV is charged for every two days.

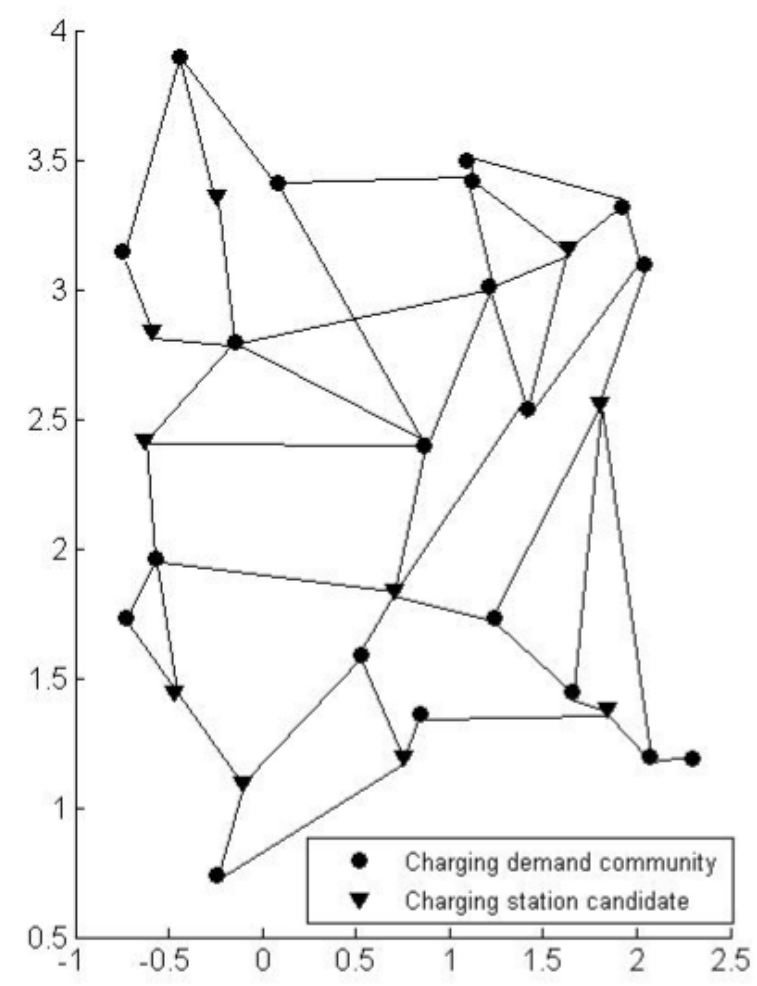

FIGURE IV. TRAFFIC NETWORK AND LOCATIONS OF CHARGING DEMAND COMMUNITIES AND CHARGING STATION CANDIDATES

TABLE I. EV OWNERSHIP AND LOCATION OF CHARGING DEMAND COMMUNITIES

\begin{tabular}{|c|c|c|c|}
\hline $\begin{array}{c}\text { Number of } \\
\text { communities }\end{array}$ & Abscissa & Ordinate & $\begin{array}{c}\text { Ownership of } \\
\text { EV }\end{array}$ \\
\hline 1 & 2.30 & 1.19 & 130 \\
\hline 2 & 2.04 & 3.10 & 85 \\
\hline 3 & 2.07 & 1.20 & 123 \\
\hline 4 & 1.92 & 3.32 & 100 \\
\hline 5 & 1.12 & 3.42 & 120 \\
\hline 6 & 1.21 & 3.01 & 75 \\
\hline 7 & 1.42 & 2.54 & 80 \\
\hline 8 & 1.65 & 1.45 & 130 \\
\hline 9 & 0.19 & 3.50 & 95 \\
\hline 10 & 0.86 & 2.40 & 90 \\
\hline 11 & -0.44 & 3.90 & 92 \\
\hline 12 & 0.08 & 3.41 & 78 \\
\hline 13 & 1.24 & 1.73 & 75 \\
\hline 14 & 0.53 & 1.59 & 120 \\
\hline $\begin{array}{c}\text { Number of } \\
\text { communities }\end{array}$ & Abscissa & Ordinate & Ownership of \\
\hline 15 & -0.75 & 3.15 & 123 \\
\hline 16 & -0.24 & 0.74 & 237 \\
\hline 17 & -0.14 & 2.80 & 117 \\
\hline 18 & -0.73 & 1.73 & 100 \\
\hline 19 & 0.84 & 1.36 & 107 \\
\hline 20 & -0.57 & 1.96 & 113 \\
\hline
\end{tabular}


TABLE II. LOCATIONS OF CHARGING STATION CANDIDATES

\begin{tabular}{|c|c|c|c|}
\hline $\begin{array}{c}\text { Number of } \\
\text { candidates }\end{array}$ & Location & $\begin{array}{c}\text { Number of } \\
\text { candidates }\end{array}$ & Location \\
\hline 1 & $-0.59,2.84$ & 6 & $0.71,1.84$ \\
\hline 2 & $-0.24,3.36$ & 7 & $0.75,1.20$ \\
\hline 3 & $-0.63,2.42$ & 8 & $-0.11,1.10$ \\
\hline 4 & $1.63,3.16$ & 9 & $-0.47,1.45$ \\
\hline 5 & $1.80,2.56$ & 10 & $1.84,1.38$ \\
\hline
\end{tabular}

Other parameters in the case are given in table 3.

TABLE III. OTHER PARAMETERS IN THE CASE

\begin{tabular}{|c|c|c|c|}
\hline Parameters & Value & Parameters & Value \\
\hline $\begin{array}{c}\text { Charging station } \\
\text { construction basic } \\
\text { cost(10000Yuan) }\end{array}$ & 100 & $\begin{array}{c}\text { Power loss per } \\
\text { 100KM(KWH) }\end{array}$ & 20 \\
\hline $\begin{array}{c}\text { Charging station } \\
\text { construction capacity } \\
\text { cost(10000Yuan/KVA) }\end{array}$ & 0.25 & $\begin{array}{c}\text { Average daily } \\
\text { distance(KM) }\end{array}$ & 200 \\
\hline Investment limitation & 5000 & $\begin{array}{c}\text { Road condition } \\
\text { coefficient }\end{array}$ & 1.2 \\
\hline Load rate of stations & 0.75 & $\begin{array}{c}\text { Annual charging } \\
\text { times }\end{array}$ & 180 \\
\hline $\begin{array}{c}\text { Years in return of capital } \\
\text { investment(year) }\end{array}$ & 20 & $\begin{array}{c}\text { Charger } \\
\text { simultaneity rate }\end{array}$ & 0.7 \\
\hline Discount rate & 0.1 & $\begin{array}{c}\text { Loss } \\
\text { cost(Yuan/KM) }\end{array}$ & 2.5 \\
\hline Demand factor & 0.8 & $\begin{array}{c}\text { Battery capacity of } \\
\text { VE(KWH) }\end{array}$ & 60 \\
\hline Charging efficiency & 0.9 & $\begin{array}{c}\text { Initial electric } \\
\text { charge for EV(\%) }\end{array}$ & 50 \\
\hline Maximum iteration limit & 200 & \multicolumn{2}{|c|}{ into the model } \\
\hline
\end{tabular}

All parameters are substituted into the model and CHS algorithm is used to solve it. After 600 times iterations, the third planning obtained is able to satisfy the constraint of battery capacity. This means that the battery capacity constraint can, to a certain extent, avoid the problem of the service radius constraint. The location and capacity of charging station after optimization are shown in table 4.

TABLE IV. LOCATION AND CAPACITY OF CHARGING STATIONS AFTER OPTIMIZATION

\begin{tabular}{|c|c|c|}
\hline Number & Location & Capacity \\
\hline 2 & $-0.24,3.36$ & 2900 \\
\hline 4 & $1.63,3.16$ & 3000 \\
\hline 6 & $0.71,1.84$ & 3000 \\
\hline 9 & $-0.47,1.45$ & 3700 \\
\hline 10 & $1.84,1.38$ & 3000 \\
\hline
\end{tabular}

As can be seen from the table above, after considering all constraints, the demand for EV charging in the planning area can be met by the above 5 charging stations, the total annual cost is 1.22 million Yuan. It can also be seen that due to the different geographical location of charging stations, the planning of the capacity is not the same, which is conducive to the full and efficient use of resources.

\section{CONCLUSIONS}

The planning of EV charging station is a complex programming problem involving the user's demand, economic benefit, geographical topology and many other factors. In this paper, the minimum annual cost function model is established, and the traditional service radius constraint is replaced by the battery capacity constraints, which makes the planning model more rigorous and scientific. The satisfactory solution of the model is obtained by using the chaos and harmony search algorithm, which makes the charging demand of the electric vehicle users in the planning area be satisfied. Example analysis shows that the model and algorithm used in this paper has some scientificalness, and can provide some reference for engineering planning.

\section{REFERENCES}

[1] SU Ling, ZHANG Jianhua, WANG Li, et al, Study on some key problems and technique related to microgrid, Power System Protection and Control, vol.38, no.19, pp.235-239, 2010.

[2] KHODAYAR M, BARATI M, SHAHIDEHPOUR M, Integration of high reliability distribution system in microgrid operation , Smart Grid, vol.3,no.4, pp.1997-2006, 2012.

[3] LI Yin, ZHANG Boming, ZHAO Jinquan, et al. An online optimal power flow approach based on extended linear programming $[\mathrm{J}]$, Automation of Electric Power Systems, vol.30,no.5, pp.18-23, 2006.

[4] CHEN C C, WANG S C. Branch and bound scheduling for thermal generating units[J]. IEEE Trans on Energy Conversion, vol.8,no.2, pp184-189,1993.

[5] WANG Chengshuan, LIU Tao, XIE Yinghua, Sbustation locating and sizing based on hybrid genetic algorithm[J]. Automation of Electric pOwer System, vol.25, no.6, pp40-44, 2006

[6] R. Nicole, "Title of paper with only first word capitalized," J. Name Stand. Abbrev., in press.

[7] TURTON H, MOURA F, Vehicle-to-grid systems for sustainable development : an integrated energy analysis, Technological Forecasting and Social Change, vol.75, no.8, pp.1091-1108, 2008.

[8] ANDERSEN P, MATHEWS J, MORTEN R, Integrating private transport into renewable energy policy : the strategy of creating intelligent recharging grids for electric vehicles , Energy Policy, vol.37, no.7, pp.2481-2486, 2009.

[9] SABER A, VENAYAGAMOORTHY G, Plug-in vehicles and renewable energy sources for cost and emission reductions, IEEE Transactions on Industrial Electronics, vol.58, no.4, pp.1229-1238, 2011.

[10] YU Dayang, HUANG Haili, LEI Ming, et al, $\mathrm{CO}_{2}$ reduction benefit by coordinated dispatch of electric vehicle charging and wind power, Automation of Electric Power Systems, vol.36, no.10, pp.14-18, 2012.

[11] KOU Lingfeng, LIU Zifa, ZHOU Huan. Modeling algorithm of charging station planning for regional electric vehicle[J]. Modern Electric Power, vol.27, no.4, pp.44-48, 2010.

[12] TANG Xianggang, LIU Junyong, LIU Yongbo. Electric Vehicle Charging Station Planning Based on Comtational Geometry Method[J]. Automation of Electric Power System, vol.36, no.8, pp24-30, 2011.

[13] LI Yuehong, WAN Pin, WANG Yonghua, et al, Optimal linear cooperation spectrum sensing method based on chaos harmony search algorithm, Journal of Computer Applications, vol.32, no.9, pp.24122417, 2012. 